\title{
Impact of physical properties and accumulation rate on pore close-off in layered firn
}

\author{
S. A. Gregory, M. R. Albert, and I. Baker \\ Thayer School of Engineering, Dartmouth College, Hanover, NH 03766, USA \\ Correspondence to: M. R. Albert (mary.r.albert@dartmouth.edu) \\ Received: 30 April 2013 - Published in The Cryosphere Discuss.: 13 June 2013 \\ Revised: 20 November 2013 - Accepted: 2 December 2013 - Published: 13 January 2014
}

\begin{abstract}
Investigations into the physical characteristics of deep firn near the lock-in zone through pore close-off are needed to improve understanding of ice core records of past atmospheric composition. Specifically, the permeability and microstructure profiles of the firn through the diffusive column influence the entrapment of air into bubbles and thus the ice age-gas age difference. The purpose of this study is to examine the nature of pore closure processes at two polar sites with very different local temperatures and accumulation rates. Density, permeability, and microstructure measurements were made on firn cores from the West Antarctic Ice Sheet (WAIS) Divide, a site that has moderate accumulation rates with a seasonal climate archive, and Megadunes in East Antarctica, a site that is a natural laboratory for accumulation rate effects in the cold low-accumulation desert. We found that the open pore structure plays a more important role than density in predicting gas transport properties, throughout the porous firn matrix. For firn below $50 \mathrm{~m}$ depth at both WAIS Divide and Megadunes, finer-grained layers experience close-off shallower in the firn column than do coarser-grained layers, regardless of which grain size layer is the denser layer at depth. Pore close-off occurs at a critical open porosity that is accumulation rate dependent. Defining pore close-off at a critical open porosity for a given accumulation rate as opposed to a critical total porosity accounts for the pore space available for gas transport. Below the critical open porosity, the firn becomes impermeable despite having small amounts of interconnected pore space. The lowaccumulation sites, with generally coarse grains, close off at lower open porosities $(\sim<10 \%)$ than the open porosity $(\sim>10 \%)$ of high-accumulation sites that have generally finer grains. The microstructure and permeability even near the bottom of the firn column are relic indicators of the nature
\end{abstract}

of accumulation when that firn was at the surface. The physical structure and layering are the primary controlling factors on pore close-off. In contrast to current assumptions for polar firn, the depth and length of the lock-in zone is primarily dependent upon accumulation rate and microstructural variability due to differences in grain size and pore structure, rather than the density variability of the layers.

\section{Introduction}

As an archive for past atmospheric composition, the polar ice sheets play an important role in understanding climate change, both natural and anthropogenic in origin. The surface of the Greenland and Antarctic ice sheets is covered in a $60-120 \mathrm{~m}$-thick layer of firn, multiyear snow that undergoes further metamorphism with depth until it becomes solid ice at the firn-ice transition. The firn layer acts as a filter on atmospheric signals that are eventually captured within bubbles in the underlying ice. Because air within the firn column can exchange with the atmosphere until deep in the firn at the start of the lock-in zone, or at pore close-off at sites with no lock-in zone, where horizontal layers of firn become impermeable, impeding vertical gas transport, the air entrapped in bubbles of the ice matrix is always younger than the ice (Schwander and Stauffer, 1984). Knowing the depth at which air can no longer exchange with the atmosphere is pivotal for determining the gas age-ice age difference. At present-day polar sites, most studies have focused on the bulk properties of the firn, and not until the recent past have studies started to include the layered nature of the firn (Albert et al., 2004; Courville et al., 2010; Freitag et al., 2004; Fujita et al., 2009; Horhold et al., 2011). 
A typical firn column can be divided into three main zones based on the dominating gas transport mechanisms operating at a given depth (Sowers et al., 1992). Gas movement in the top of the firn column, the convective zone, is dominated by convection due to highly permeable firn and/or wind pumping. Below the convective zone is the diffusive zone, where the main gas transport mechanism is molecular diffusion. Near the base of the diffusive zone is the non-diffusive or lock-in zone (LIZ) characterized by layers of firn, some of which are permeable and some are not. At the top of the LIZ is the lock-in depth (LID), the depth at which the first impermeable horizontal layer of firn impedes vertical gas exchange with the atmosphere. The bottom of the LIZ is at the close-off depth beyond which all pores are closed off from one another both vertically and horizontally and no gas transport exists.

A useful technique to examine firn microstructure is X-ray computed tomography. While X-ray computed tomography is well established in soil science (Taina et al., 2008), initial application to polar firn has only happened in the last 10-15 yr (e.g., Coleou et al., 2001; Freitag et al., 2004; Schneebeli and Sokratov, 2004). Several studies have been done using $\mathrm{X}$-ray computed tomography to examine the microstructure of polar firn. Lomonaco et al. (2011) examined the evolution of fine-grained layers from the surface through pore closeoff. Freitag et al. (2004) and Fujita et al. (2009) focused primarily on understanding how microstructure differences between fine-grained and coarse-grained firn influences the densification rate of polar firn. Other studies include the influence of microstructure, either from thick sections or Xray computed tomography on the permeability of firn at the top of the firn column (Albert et al., 2004; Courville et al., 2007; Rick and Albert, 2004). Courville et al. (2010) and Freitag et al. (2002) used 3-D reconstructions of firn cube microstructure to model centimeter-scale permeability of firn using lattice Boltzmann techniques. The specific influence of microstructure on bulk properties affecting gas transport in deep firn has not been well investigated.

Pore close-off has been studied through three approaches: (1) density predicted from densification models, (2) in situ through firn air measurements and modeling, and (3) laboratory-based permeability measurements. An inherent issue in understanding the processes controlling pore closeoff is an integration between microscale processes and macroscale processes. For example, in situ firn air measurements are taken on a meter scale over many layers of firn, while laboratory-based permeability measurements are taken on the centimeter scale and often incorporate a single homogenous firn layer. Several studies have been done in an attempt to understand the percolation nature of pore closeoff (Entig, 1993; Freitag, 2008). While macroscale processes involved with gas transport through firn are important, understanding the origins of pore close-off on a much smaller scale through the microstructural properties of the firn should provide insight for understanding gas transport through firn and for enabling improvements in firn air modeling.
The traditional assumption is that pore close-off density is site specific, and the first layers of firn to reach this density will close-off and no longer exchange air with the atmosphere. Martinerie et al. (1992) used sixteen different sites to parameterize the mean density of pore close-off based on the temperature of the sites. Parameterizing close-off with a mean density ignores the layered nature of firn and the presence of a lock-in zone. To account for the length of the lockin zone in firn densification modeling, Goujon et al. (2003) used a closed porosity of $37 \%$ to indicate the close-off depth (bottom of the lock-in zone), a closed porosity of $21 \%$ for Vostok, Antarctica, and $13 \%$ for Summit, Greenland, to indicate the lock-in depth. The thickness of present-day lockin zones tends to increase with an increase in accumulation rate (Landais et al., 2006). An increase in lock-in zone thickness at high-accumulation sites has been linked by Horhold et al. (2011) to a second period of high density variability using high-resolution density measurements. In this paper, using laboratory measurements on firn cores retrieved from Antarctica, we explore the role of microstructure including pore structure on the nature of layers in deep firn and the range of depths where pore close-off occurs.

The second approach for assessing pore close-off in polar firn is through in situ bulk firn air measurements accompanied by firn modeling. Firn air campaigns have been conducted at a number of Arctic and Antarctic sites where trace gas and isotopic fractionation are used to locate the lock-in depth. The deepest location where air can be sampled from the firn column is typically considered the close-off depth and the bottom of the lock-in zone (Clark et al., 2007; Buizert et al., 2012a; Kawamura et al., 2006; Schwander et al., 1993; Witrant et al., 2012; Etheridge et al., 1996; Trudinger, 2001; Severinghaus et al., 2001, 2010; Fabre et al., 2000; Battle et al., 2011). Firn air models have been developed to construct effective gas diffusivity profiles through a combination of forward and inverse modeling (e.g., Rommelaere et al., 1997; Trudinger et al., 1997, 2002; Buizert et al., 2012a). These models use density profiles derived from densification models to estimate an open porosity profile of an individual site. The open porosity profile is then used to predict effective diffusivity profiles for various tracer gases at the site. The effective diffusivity profile is then tuned based on measurements until a good fit is found. While this method apparently works well for present-day sites where firn air measurements are available, better parameterization of polar firn based on temperature and accumulation rate is needed in order to use firn air models accurately for firn columns existing in past environments (Brook, 2013). Schwander et al. (1988) demonstrated a relationship for tortuosity as a function of porosity at Siple Station, Antarctica, but this relationship does not account for microstructural differences in polar firn from site to site. In an attempt to better characterize gas transport and open porosity, Freitag et al. (2002) fitted both gas diffusivity and permeability to open porosity using two power law functions with exponents 2.1 and 3.4, respectively, 
for firn from Summit, Greenland. The results from Schwander et al. (1988), Fabre et al. (2000) and Freitag et al. (2002) agree reasonably well for open porosities greater than 0.2 but diverge at low porosities, and none account for the layered nature of firn or density variability of the lock-in zone.

This study aims to better understand the role firn microstructure plays in controlling gas transport in deep firn and to investigate the validity of using density (bulk or local) to predict gas transport in polar firn, including pore closeoff, by comparing firn structure from two Antarctic sites, WAIS Divide and Megadunes, which are both sites that do not experience melt but that have very different local climates. The WAIS Divide site in West Antarctica has a mean annual temperature of $-31^{\circ} \mathrm{C}$ and gets significant annual accumulation. The very cold Megadunes site in the polar desert of East Antarctica is a natural laboratory for the study of investigation of accumulation rate on firn properties (Courville et al., 2007). Our microstructural analysis, density and permeability measurements show the importance of grain and pore structure over local density and open porosity in controlling gas transport and the pore close-off process. We investigate links between accumulation rate, pore structure and gas transport properties affecting permeability, gas diffusivity and pore close-off in deep firn.

\section{Methods}

\subsection{Visual stratigraphy}

Stratigraphic layering of the firn was observed and recorded using a backlit light table in a cold room at the Cold Regions Research and Engineering Laboratory in Hanover, NH. Meter-long core sections were placed on the light table where grain size and wind crusts were recorded to the $1 \mathrm{~mm}$ scale. Relative grain size was qualitatively described using a fivetier scale from coarse to fine for each meter length section. Coarse grains and fine grains were defined relative to other layers within the meter-long section. The most coarsegrained layers meter by meter are identified as coarse, while the most fine-grained layers are identified as fine grain. All other firn grain layers are classified into four categories between these two identifiers. In this way, the quantitative measurements of a fine-grain layer at the surface and a fine-grain layer at depth are not the same; the qualitative scale was done in order to describe the layering. Comparison between the WAIS Divide site and the Megadunes site was also done visually with a backlit light table in which the coarse-grain layers at WAIS Divide below $55 \mathrm{~m}$ were observed to be smaller relative to the fine-grain layers at Megadunes below $55 \mathrm{~m}$. Samples of 5-10 cm of similar grain size were cut for further analysis. Emphasis was put on obtaining a single homogenous layer of firn per sample whenever possible, in order to facilitate comparisons of the measured transport properties with quantitative microscopy results.

\subsection{Bulk density}

Bulk density measurements were made on the same $5-10 \mathrm{~cm}$ resolution samples using volumetric measurements and the mass of the sample. Error in density measurements was small, with less than $0.5 \%$ standard deviation for 10 repeat measurements on a single sample. The mass of the sample from scale measurement is accurate to $1 \%$, and the volume of the sample calculated from caliper measurements is accurate to within approximately $2 \%$. To increase the accuracy of bulk property measurements, broken and chipped samples, not of an ideal cylindrical shape, were not included in bulk density or permeability measurements and are not reported in this paper.

\subsection{Permeability}

Permeability measurements were made using the methods developed by Albert et al. (2000), and used for example in Rick and Albert (2004), and Courville et al. (2007). Using a custom apparatus that had been verified on glass beads, air was drawn through a firn sample, and the associated flow rate and pressure drop across the sample were measured, along with temperature and barometric pressure. A variety of flow rates was employed. Each measured flow rate and associated measured pressure drop was used with Darcy's law to calculate the permeability. Flow rates of air through the samples were kept within the laminar flow regime where Darcy's Law holds true:

$v=\frac{k}{\mu} \cdot \frac{\mathrm{d} P}{\mathrm{~d} x}$,

where $k$ is the permeability constant, $\mu$ is the air viscosity, $\mathrm{d} P$ is the pressure differential, $\mathrm{d} x$ is the height of the sample and $v$ is the flow velocity. Before measurements were taken the permeameter was calibrated using glass bead samples. Calibration was complete when measured glass bead permeability fell within the accepted literature values. Ten measurements with ten different flow rates were done on each sample and usually fell within $5-10 \%$ of one another. At very low permeabilities fewer but at least five measurements were made on each sample due to the low flow rates needed to stay within the laminar flow regime. The lowest permeability measured was $1 \times 10^{-12} \mathrm{~m}^{2}$. All samples whose measurements fell below the range of the sensitive pressure transducer were considered impermeable and assigned permeability values of $0 \mathrm{~m}^{2}$.

\subsection{Microcomputed tomography}

Firn microstructure properties were obtained using X4-ray microtomography. A Skyscan 1172 model microCT was used in a cold room. Scans were run at $40 \mathrm{kV}$, a $250 \mu \mathrm{A}$ current intensity, and a rotation step of $0.7^{\circ}$ completing $180^{\circ}$ rotation for each run. A total of 275 shadow images were obtained and reconstructed using Skyscan's NRecon software 
for two-dimensional slice reconstruction. The resolution of the images obtained is $14.8 \mu \mathrm{m}$ in which each voxel obtained represents a three-dimensional cube with $14.8 \mu \mathrm{m}$ side length. Firn samples were cut to $1 \mathrm{~cm}$ width $\times 1 \mathrm{~cm}$ width $\times 1.5 \mathrm{~cm}$ height segments from the center of the $5-10 \mathrm{~cm}$ samples used in density and permeability measurements. The volume of interest analyzed for microstructure properties was $538 \times 538 \times 673$ voxels, or $8 \mathrm{~mm} \times 8 \mathrm{~mm} \times 10 \mathrm{~mm}$ in size. For thresholding 256 grey levels were used and a thresholding value of 89 was set between the air and the ice phase. The large difference in linear attenuation coefficients (X-ray absorption) between ice and air enables a simple thresholding limit to be used to binarize the images. To reduce noise and minimize falsely counting incorrectly binarized voxels as pores or small ice clusters, all white specs less than 25 voxels surrounded by black voxels were removed and vice versa. Image analysis on both the ice phase and pore phase was done to obtain the microstructure properties of both the ice structure and pore structure of the firn sample.

The microstructural properties, derived using Skyscan's CTan software, include total porosity, open porosity, closed porosity, structural model index, surface-to-volume $(S / V)$ ratio, and anisotropy. The total porosity of the sample is determined by counting the total number of voxels present for the phase being analyzed and dividing that by the total number of voxels within the region of interest. Open porosity is defined as any pore that intersects with the edge of the region of interest at least once. From total and open porosity values, closed porosity of a sample can quickly be determined through subtraction. To account for closed pores that were cut during sample preparation, pore size distribution was determined for all samples where the majority of closed pores had volumes of $1 \mathrm{~mm}^{3}$ or less. Through individual object analysis all pores with a center within $0.62 \mathrm{~mm}$ (the radius of a $1 \mathrm{~mm}^{3}$ spherical pore) of the edge of the region of interest were considered closed, and open porosity and closed porosity were adjusted accordingly for each sample.

Structure model index (SMI) gives an estimation for the type of shape present in the analyzed phase. SMI values of 0,3 and 4 correspond to an ideal plate, cylinder, and sphere, respectively. Calculation of SMI follows that developed by Hildebrand and Rüegsegger (1997) in which one voxel thickness is added to the surface of the phase analyzed. SMI is then calculated as follows:

$\mathrm{SMI}=6 \frac{S^{\prime} \cdot V}{S^{2}}$

where $S^{\prime}$ is the change in surface area between the initial surface area and the artificially increased surface area, $S$ is the original surface area, and $V$ is the initial volume of the analyzed phase. For convex shapes, SMI is positive while concave structures have negative SMI values. The surfaceto-volume ratio gives the ratio of the analyzed phase surface area to the volume of the phase in three dimensions. It gives estimation of how tortuous an object is where a low $S / V$ indicates less complexity in shape than a high $S / V$ (morphometric parameters measured by SkyscanTM CT-analyser software, Bruker-MicroCT CT-Analyser, http: //www.skyscan.be).

Anisotropy is a measure of alignment or three-dimensional symmetry within the region of interest. The value of anisotropy is determined using the mean intercept length: the length of a line traveling through an object divided by the number of times the line crosses the analyzed phase. The higher the mean intercept length the more the object is aligned in a single direction, indicating a high degree of anisotropy. The mean intercept length is found at many 3-D angles within the region of interest, and each MIL is plotted to create an ellipsoid. The ellipsoid is described using an orthogonal tensor whose maximum and minimum eigenvalues are used to determine the degree of anisotropy as follows:

$\mathrm{DA}=1-\left(\frac{\min _{\text {eigenvalue }}}{\text { max }_{\text {eigenvalue }}}\right)$.

Using this definition, the degree of anisotropy (DA) ranges from a value of 1 , totally isotropic, to infinity, totally anisotropic (morphometric parameters measured by SkyscanTM CT-analyser software, Bruker-MicroCT CTAnalyser, http://www.skyscan.be).

\section{Site characteristics}

The Megadunes and WAIS Divide sites were chosen to provide two contrasting local climates to understand how climate influences firn microstructure, gas transport and pore close-off. WAIS Divide, which was chosen for drilling of a deep ice core for climate science, is the Antarctic counterpart to Summit, Greenland, and it has been described by Battle et al. (2011) as an intermediate site in terms of temperature and accumulation rate. The Megadunes site in the extremely cold polar desert of East Antarctica was chosen for comparison because it essentially constitutes a natural laboratory for the study of effect of accumulation rate. Courville et al. (2007) provide a complete description of the manner in which two different accumulation rates exist under the same temperature and other climatic conditions at Megadunes. The windward faces of the low-amplitude, long-wavelength antidunes experience accumulation, while the leeward faces undergo zero accumulation or ablation. As the dunes slowly migrate upwind over decades, past dunes are slowly buried, and the resulting layering and firn structure provide enduring evidence of alternation between accumulation and hiatus firn layers as evidence of the layers persist down the firn column (Courville et al., 2007).

\subsection{Megadunes}

Measurements of firn air and extraction of a firn core from a megadunes site in East Antarctica were accomplished 
at an undisturbed site in December 2004-January 2005 at $80.77914^{\circ} \mathrm{S}, 124.48796^{\circ} \mathrm{E}$. Courville et al. (2007) thoroughly describe the site details and near-surface measurements, and Severinghaus et al. (2010) describe in situ firn air measurement results. The average temperature at the site is $-49^{\circ} \mathrm{C}$ with an accumulation rate less than $4 \mathrm{~cm}$ weq $\mathrm{a}^{-1}$. In situ firn air measurements at Megadunes done by Severinghaus et al. (2010) indicate a LIZ from $64.5 \mathrm{~m}$ to $68.5 \mathrm{~m}$. The convective zone at Megadunes is notably very thick, reaching a depth of $\sim 23 \mathrm{~m}$ (Severinghaus et al., 2010).

\subsection{WAIS divide}

The WDC05C firn core was retrieved from a previously undisturbed site at $79.46300^{\circ} \mathrm{S}, 112.12317^{\circ} \mathrm{W}$ near the WAIS Divide ice coring site for firn air measurements in December 2005-January 2006 (Battle et al., 2011). The mean annual temperature at the site is $-31{ }^{\circ} \mathrm{C}$ and the average accumulation rate is $21 \mathrm{~cm} \mathrm{weq} \mathrm{a}^{-1}$ (Banta et al., 2008). The accumulation rate and average temperature at the site are both significantly higher than those at the Megadunes location. From in situ firn air measurements done by Battle et al. (2011) a LIZ exists from approximately $66 \mathrm{~m}$ to $76.54 \mathrm{~m}$. Similar to other high-accumulation sites, the convective zone is small, likely ranging between $1.4 \mathrm{~m}$ and $5.2 \mathrm{~m}$ in depth (Battle et al., 2011).

\section{Results}

This paper primarily discusses the nature of firn at two depth ranges: one at $30-36 \mathrm{~m}$, which is within the diffusive zone, and a deeper range encompassing just above the lock-in zone through pore close-off. Measurements of density, permeability, and microstructure in very deep firn are investigated starting at $55 \mathrm{~m}$, approximately ten meters above the start of the LIZ at both sites that had been determined through in situ firn air measurements, to a few meters below the close-off depth at each site. The deepest measurements at WAIS Divide were $78 \mathrm{~m}$, while the deepest measurements done at Megadunes were $75 \mathrm{~m}$. Including measurements of gas transport and microstructure above the LIZ enabled examination of trends and how they relate to pore close-off in both bulk and microstructural properties. To relate relationships observed in deep firn to firn at shallower depths, a series of permeability and density measurements were done on each core from 30 to $36 \mathrm{~m}$, and are reported here, along with the complete bulk density profile of WAIS Divide. Analysis at all depths for both cores includes both fine-grained and coarse-grained firn layers.

Comparison of bulk properties taken from $5-10 \mathrm{~cm}$-long samples to microstructural properties taken from $8 \mathrm{~mm} \times$ $8 \mathrm{~mm} \times 10 \mathrm{~mm}$ was done on visually homogenous $5-10 \mathrm{~cm}-$ long samples. By avoiding layered samples, the small microCT samples were representative of the larger single firn layered samples used for density and permeability measurements, enabling a valid comparison of properties between the two sample sizes. While firn air campaigns typically retrieve gas samples coming from several layers of firn on the decimeter to meter scale, gathering a more macroscale interpretation that inherently confounds effects of properties and processes across multiple scales, a detailed inspection of firn microstructure (grain size, open porosity, closed porosity, and pore structure) and its evolution with depth provides insight into the microscale processes involved. Efforts to relate microstructure and firn permeability to the percolation process have been discussed by Entig (1993) and Freitag (2008), and are beyond the scope of this paper.

\subsection{Permeability and density}

Density and permeability measurements made between 30 and $36 \mathrm{~m}$ and between 55 and $80 \mathrm{~m}$ at Megadunes and WAIS Divide are displayed in Fig. 1. For both sites, the 30-36 m depths are many meters above the lock-in zone, and the lockin zone falls within the $55-80 \mathrm{~m}$ depths. The firn at the initiation of the lock-in zone at Megadunes originated at an accumulation site when that firn was on the surface. It can be seen from Fig 1a and $\mathrm{b}$ that in the $30-36 \mathrm{~m}$ depths above the lock-in zone, the Megadunes site is much more permeable than the WAIS Divide site, but their density profiles at this depth range are similar. Figure 1c shows that even for a given density in the $30-36 \mathrm{~m}$ depth range, Megadunes firn is more permeable than WAIS Divide firn, above the lock-in zone.

The relationships are different within the lock-in zone. For depths between 55 and $80 \mathrm{~m}$ just above and within the lockin zone, it can be seen from Fig. 1d and e that Megadunes firn is denser than WAIS Divide but the permeability profiles are similar. Very near and within the lock-in zone, the relationship existing between density and permeability (Fig. 1f) shows that Megadunes firn is more permeable for any given density than is the WAIS Divide firn. The LID, defined as the depth where multiple sequential samples are impermeable, is at $64.4 \mathrm{~m}$ at Megadunes and $63.8 \mathrm{~m}$ at WAIS Divide, indicated by a red and black line, respectively.

\subsection{Microstructure}

Microstructure imaging helps to understand the reasons for different density and permeability profiles at Megadunes and WAIS Divide. Figures 2 and 3 display three-dimensional reconstructions obtained using microcomputed tomography. The width and thickness of the reconstructed firn cubes is $8 \mathrm{~mm}$ while the height is $10 \mathrm{~mm}$. Visually Megadunes firn (Fig. 2) has larger but less total pore space at an equivalent depth than WAIS Divide (Fig. 3). The pore structure at WAIS Divide also looks more complex and divided. For both sites, total pore space decreases and the occurrence of bubbles increases with depth. 

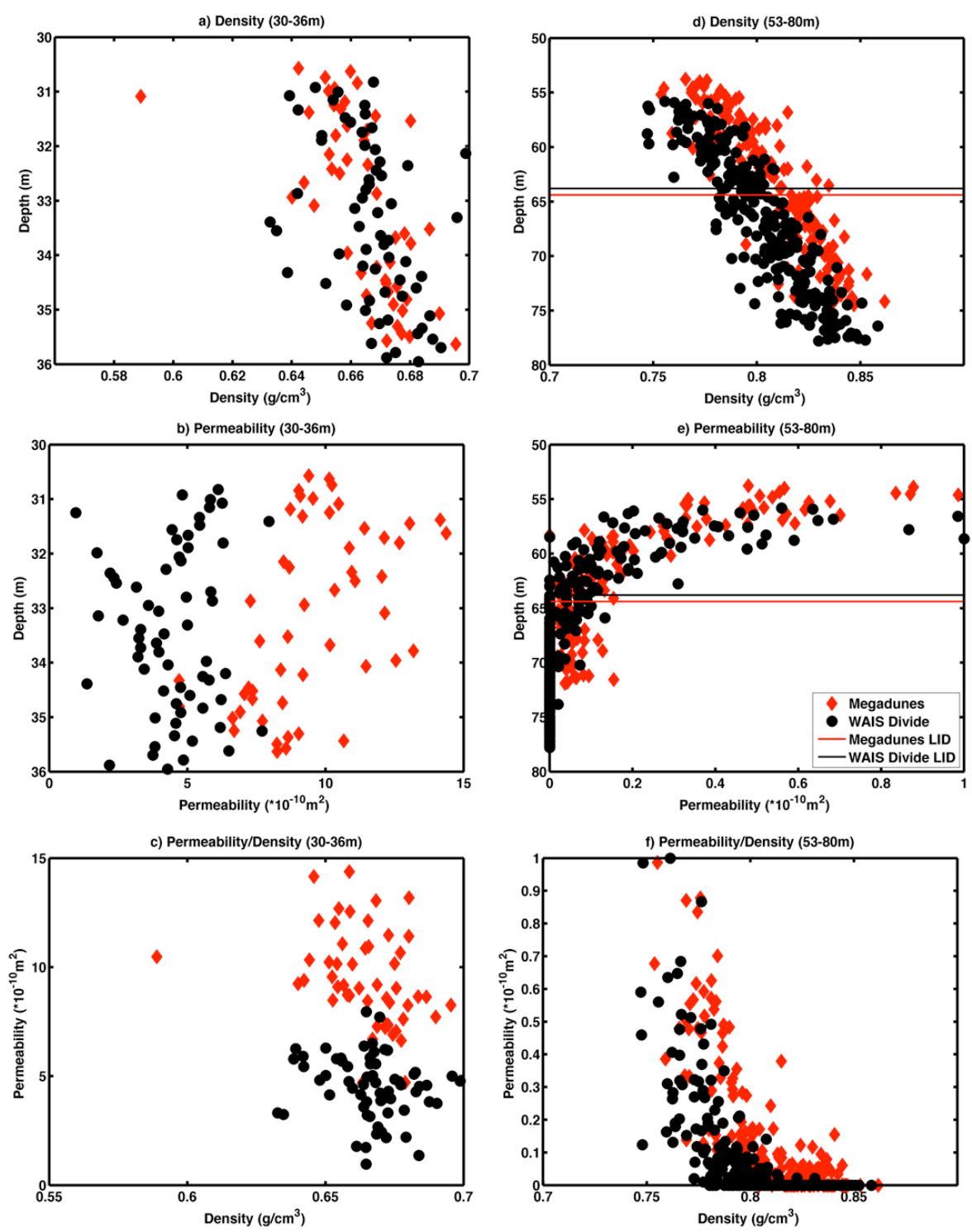

Fig. 1. (a) Density 30-36 m, (b) permeability 30-36 m, (c) density-permeability relationship 30-36 m, (d) density 55-80 m, (e) permeability 55-80 m, (f) density-permeability relationship 55-80 m. In all graphs, black circles indicate data from WAIS Divide and red diamonds indicate data from Megadunes.

Microstructural analysis enables quantification and validation of differences in visual observations seen between the two sites. The SMI profile, an indicator of pore shape, is similar for Megadunes and WAIS Divide with depth. The pore structure at Megadunes and WAIS Divide (Fig. 4) ranges from semi-cylindrical, an average value of 2 at $56 \mathrm{~m}$ with increasing SMI, to average values of 2.7 at $75 \mathrm{~m}$, indicative of an almost perfectly cylindrical pore structure. Toward the end of the LIZ (70-75 m) the pore structure is very close to cylindrical with some high end values reaching 3.5. The data from 56 to $75 \mathrm{~m}$ show a trend in increasing SMI with depth that would likely continue to increase to a value of 4 (perfect spheres) around the firn-ice transition. $S / V$ character- izes the complexity of a structure and can serve as a proxy for tortuosity (Spaulding et al., 2011). Megadunes firn has consistently lower values of $S / V$ of the pore space than WAIS Divide, indicating a less tortuous pore structure at a given depth. $S / V$ at Megadunes is lower than at WAIS Divide at equivalent densities as well (Fig. 4). Anisotropy profiles of both sites overlap and are almost completely isotropic. Using these microstructure parameters to describe pore structure, Megadunes and WAIS Divide pores are isotropic and evolving from semi-cylindrical type shapes at mid-depths toward cylinders in the LIZ. Occasionally, within the LIZ, firn layers consist of a pore structure closer to spheres, and the frequency of these layers increases with depth. The difference 


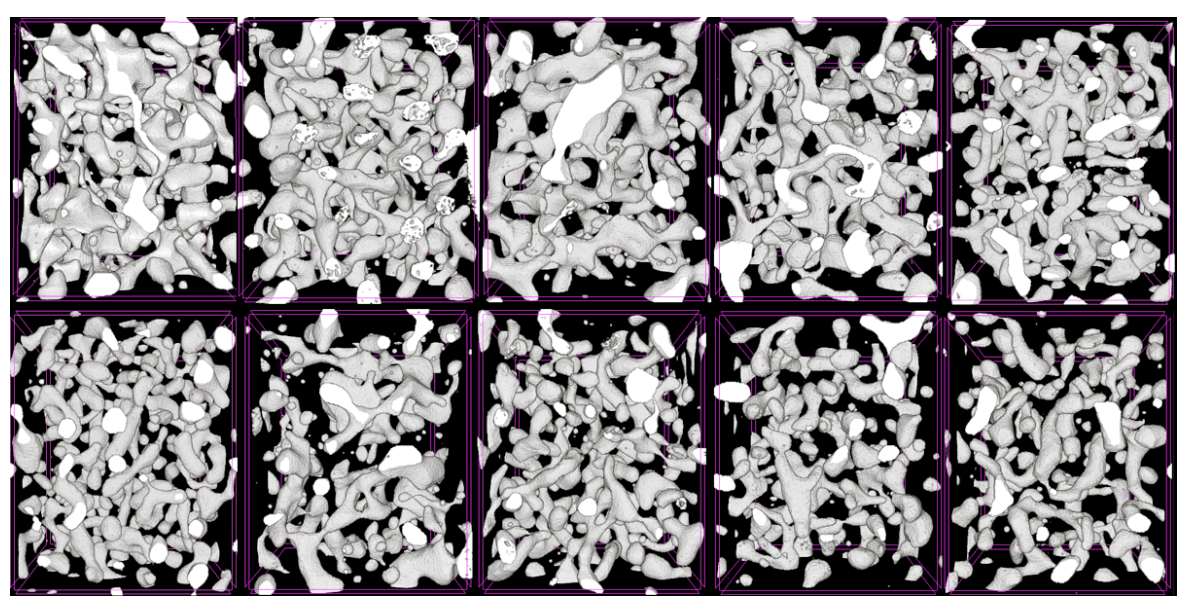

Fig. 2. Megadunes 3-D pore space reconstruction where white is the pore phase. Top row (from left to right): $56.25 \mathrm{~m}, 58.28 \mathrm{~m}, 60.43 \mathrm{~m}$, $62.75 \mathrm{~m}, 64.98 \mathrm{~m}$. Bottom row (from left to right): $66.79 \mathrm{~m}, 68.17 \mathrm{~m}, 70.30 \mathrm{~m}, 72.34 \mathrm{~m}, 73.27 \mathrm{~m}$.

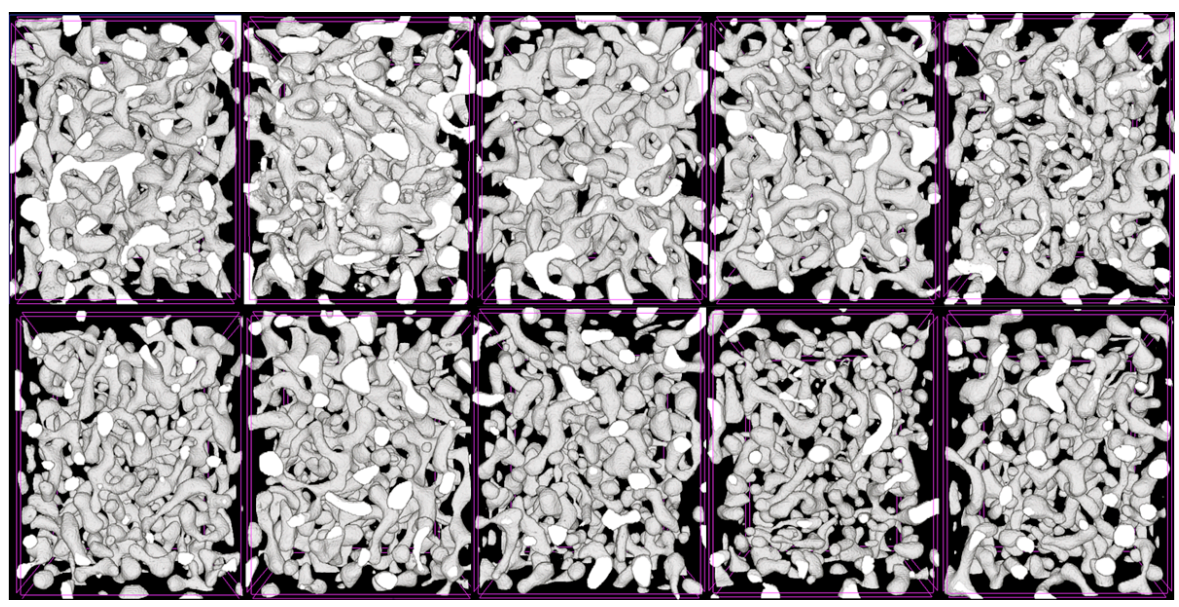

Fig. 3. WAIS Divide 3-D pore space reconstruction where white is the pore phase. Top row (from left to right): $56.36 \mathrm{~m}, 58.52 \mathrm{~m}, 60.45 \mathrm{~m}$, $62.44 \mathrm{~m}, 64.61 \mathrm{~m}$. Bottom row (from left to right): $66.56 \mathrm{~m}, 67.38 \mathrm{~m}, 70.56 \mathrm{~m}, 73.51 \mathrm{~m}, 74.50 \mathrm{~m}$.

occurs in tortuosity of the pore matrix, indicated by $S / V$, where WAIS Divide is more tortuous than Megadunes at a given depth and at a given density.

\subsection{Porosity}

Porosity of polar firn decreases with depth as firn densifies and reflects the amount of space that is not filled by ice for a given volume at a given depth in the firn column. Total porosity of polar firn is the ratio of the air space to the ice matrix within a given volume. Total porosity is a direct reflection of density in porous media, and is generally calculated directly from the measured density of bulk samples as

$P=1-\left(\frac{\rho}{\rho_{\text {ice }}}\right)$ where $P$ is the porosity of the sample, $\rho$ is the density of the sample, and $\rho_{\text {ice }}$ is the density of pure ice $\left(0.917 \mathrm{~g} \mathrm{~cm}^{-3}\right)$. While total porosity is derived from the density of a sample, open porosity reflects the amount of interconnected interstitial air space available for gas transport. All pores categorized as open are assumed to connect via the complex pore network to the atmosphere. In contrast, closed porosity indicates the amount of air volume completely surrounded by ice, where interstitial gas transport cannot occur. All porosity measurements in this study were derived from microcomputed tomography analysis on individual firn cubes.

Figure 5a shows that both total porosity and open porosity of Megadunes firn is consistently lower than WAIS Divide firn at a given depth near pore close-off. Despite having lower open porosity, the less complex and less tortuous pore matrix causes Megadunes firn to have larger and straighter air flow channels, which leads Megadunes firn to be more permeable 

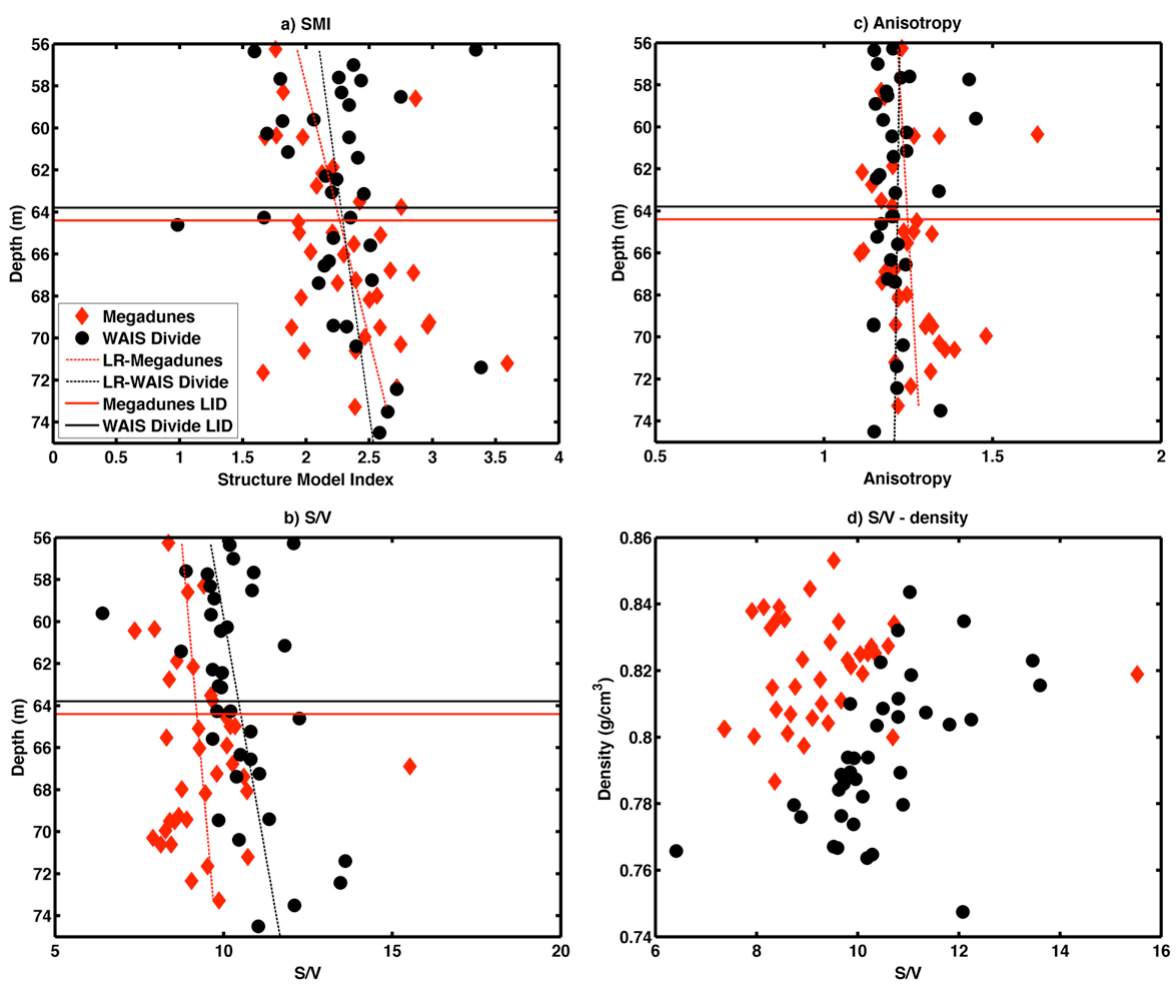

Fig. 4. (a) Structure model index, (b) surface-to-volume ratio, (c) anisotropy, (d) surface-to-volume ratio vs. density for deep firn at Megadunes (red diamonds) and WAIS Divide (black circles).

than firn at WAIS Divide, for a given density. A less tortuous pore structure allows for greater air movement than if the pore structure has many twists and turns. While total and open porosity gradually decrease with depth, closed porosity dramatically increases below the LID as seen in Fig. 5c. Closed porosity at Megadunes and WAIS Divide is less than $8 \%$ above the LID (Fig. 5). Below the LID, the rate at which closed porosity increases accelerates.

To understand the acceleration in closed porosity with no change seen in the rate of decrease in total porosity, the number and size of pores were examined. Figure 6 shows a decrease in pore size below the LID with a large increase in the total number of pores below the LID. As pore close-off progresses, WAIS Divide has more variability in the total number of pores than Megadunes within the LIZ (Fig. 6c). This is likely due to the small-scale layering of firn at highaccumulation sites in comparison to firn at low-accumulation sites (e.g., Landais et al., 2006). For pores less than $10 \mathrm{~mm}^{3}$, the pores at WAIS Divide tend to be smaller than those at Megadunes (Fig. 6b). For both sites, the abrupt increase in closed porosity at the LID corresponds with dissection of larger open pores in multiple locations to form many smaller closed or almost closed pores. The dissection of large open pores begins at an open porosity of $\sim 8 \%$ at Megadunes and $\sim 11 \%$ at WAIS Divide.
Another method used by Lomonaco et al. (2011) to observe the pore close-off process is the closed pore fraction $(\mathrm{CPF})$, defined as the number of pores divided by the total pore volume of a given sample. Plotting CPF with depth for Megadunes and WAIS Divide (Fig. 7) shows a steady CPF of $\sim 1$, slightly lower for WAIS Divide, until a depth of $63 \mathrm{~m}$. Below $63 \mathrm{~m}$, the CPF increases with depth at a constant slope through the LIZ. While the magnitude of CPF is slightly lower in the present study, the same trend in the rate of CPF increase was observed through the LIZ at Summit, Greenland, by Lomonaco et al. (2011). The increase in CPF in the LIZ of polar firn is the result of large open pores that are abruptly dissected by the ice matrix initiating the LIZ. Because firn is a layered material, variability in CPF is due to microstructural differences between fine-grain and coarse-grain firn. Thus the microstructural differences in layering between coarse-grained and fine-grained firn dictate the thickness and size of the lock-in zone.

While the Megadunes site is within the cold desert of the East Antarctic plateau, the presence of the megadune features make it different from Vostok or Dome $\mathrm{C}$, for example, which are also very cold, low-accumulation sites in East Antarctica. The presence of the megadune features make the Megadunes site a natural laboratory for the impacts of accumulation rate on firnification processes. At the Megadunes site, the enduring evidence of the relic accumulation provides a contrast to 

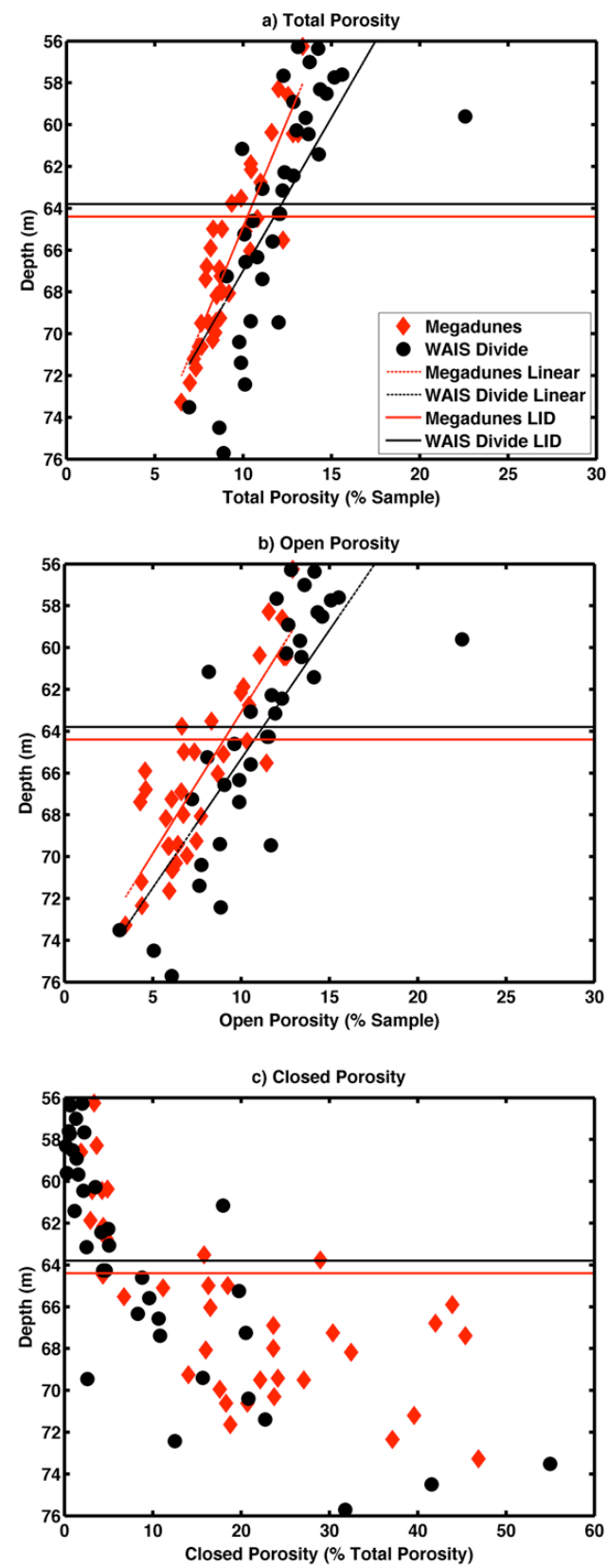

Fig. 5. (a) Total porosity $\%$ of sample, (b) open porosity $\%$ of sample and (c) closed porosity $\%$ of total porosity for deep firn at Megadunes (red diamonds) and WAIS Divide (black circles).

the rest of the firn, which had experienced accumulation hiatus, deep in the firn column. The propagation of the slightly higher accumulation rate bands of firn through the column has essentially created a firn column that is shallower than it would have been without the accumulation effect. Hence the pore close-off depth at Megadunes is shallower than at either Vostok or Dome C. Indeed, the presence of the accumulation band at Megadunes created a lock-in zone that very likely
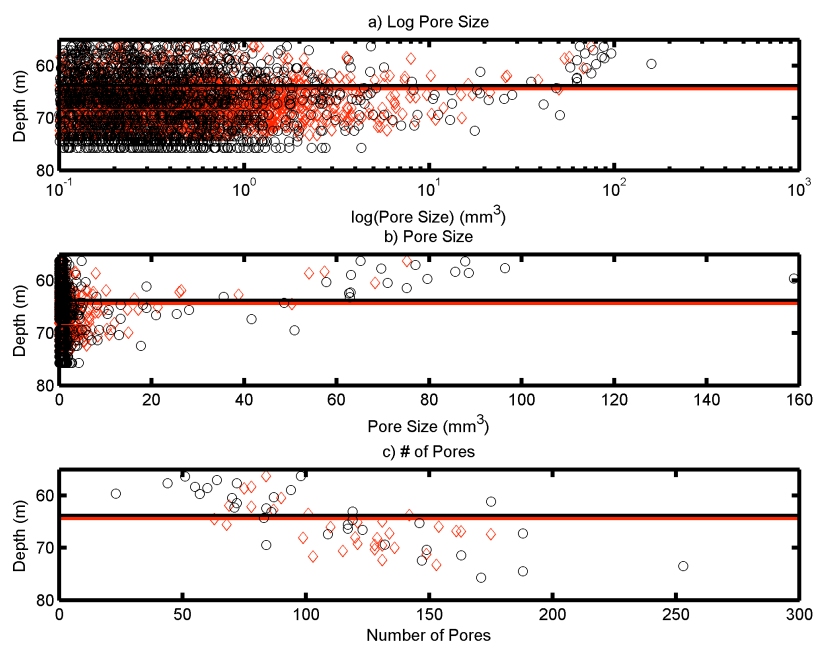

Fig. 6. (a) Profiles of log pore size, (b) pore size and (c) number of pores for pores greater than $0.001 \mathrm{~mm}^{3}$ in deep firn, $55 \mathrm{~m}$ to $80 \mathrm{~m}$, for Megadunes (red diamonds) and WAIS Divide (black circles).

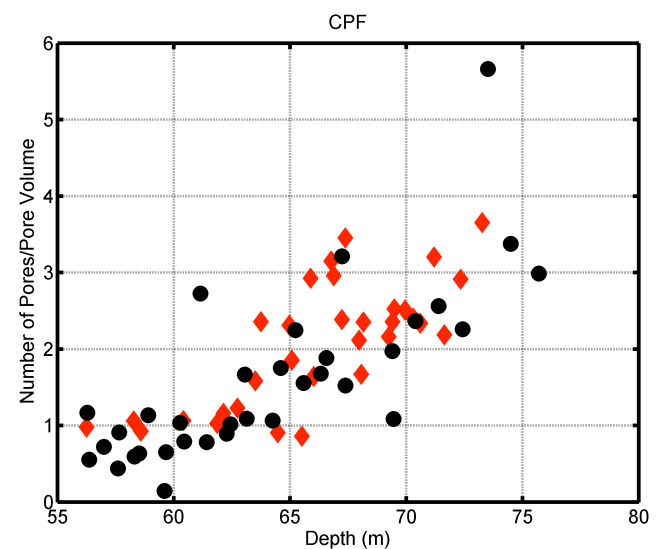

Fig. 7. Closed pore fraction (CPF) for Megadunes (red diamonds) and WAIS Divide (black circles).

would not have existed at that site without that accumulation effect.

\section{Discussion}

\subsection{Application to densification models and LIZ characteristics}

Pore close-off is traditionally defined in layered firn as the process in which individual layers of firn become impermeable and proceeds until all layers are impermeable or closed off. In the current literature on pore close-off, density controls the depth at which pore close-off occurs in an individual layer, and denser layers are thought to close off shallower than lower-density layers (Martinerie et al., 1992). Combining density-driven pore close-off and noting 
the density cross-over observed in polar firn (Hörhold et al., 2011), the first firn layers in deep firn to reach pore close-off should be the higher-density, coarser-grained layers. Hörhold et al. (2012) postulate that the firn layers with the highest impurity concentration should reach the pore close-off density first. In contrast, our observations of close-off including microstructure and density between Megadunes and WAIS Divide suggest that a combination of microstructure and grain size, rather than density, is the main driving force for an impermeable pore structure and pore close-off. Below $45 \mathrm{~m}$, Megadunes firn is consistently denser than WAIS Divide firn at a given depth, yet the permeability profiles above the LID are almost identical. In addition, the LID for both sites is also very similar: $64.4 \mathrm{~m}$ at Megadunes and $63.8 \mathrm{~m}$ at WAIS Divide. To explain the lack of a direct relationship between density (or porosity) and permeability between Megadunes and WAIS Divide, the tortuosity of the pore structure must be taken into account. Megadunes has larger grains than WAIS Divide at a given density, leading to a less tortuous pore structure and causing higher permeabilities at a given density in Megadunes firn than those observed at WAIS Divide.

It should be noted that previous estimates based on density or porosity, such as those developed by Martinerie et al. (1992) of mean pore close-off density, are close to the peak of a Gaussian type density distribution for all impermeable layers within the lock-in zone at each site (Fig. 8). Megadunes, a cold site with an average temperature of $-49^{\circ} \mathrm{C}$, has a predicted mean pore close-off density of $0.830 \mathrm{~g} \mathrm{~cm}^{-3}$, which is higher than $0.821 \mathrm{~g} \mathrm{~cm}^{-3}$ at WAIS Divide, a warmer site with an average temperature of $-31^{\circ} \mathrm{C}$ . Our results show that the density range of the distribution and thickness of the LIZ are dependent upon the microstructure variability between firn layers even though the firn layers are not annual layers but were deposited over much longer intervals of time (Albert et al., 2004). This is consistent with Landais et al. (2006), who postulated that low-accumulation sites will have smaller lock-in zones from an homogenous firn column and lack of annual layering.

Our comparison between two sites of significantly different local climates reveals that microstructure and layering, which were originally established at the surface due to the impact of accumulation rate, play a significant role in dictating deep-firn permeability and pore close-off. Continued work to identify the signatures deep in the firn of original accumulation rate impacts at additional sites should further strengthen our finding. As commonly seen in polar sites, WAIS Divide firn exhibits a density cross-over in which initially higher-density layers consisting of finer-grained firn are less dense than corresponding initially lower-density layers consisting of coarser-grained firn. While not highly pronounced on the $5-10 \mathrm{~cm}$ scale in Fig. 9, the density crossover at WAIS Divide has been noted in high-resolution density measurements on firn core WDC06A done by Breton (2011) with a minima in density variability occurring around $30 \mathrm{~m}$. In Fig. 9b, finer-grained layers become impermeable
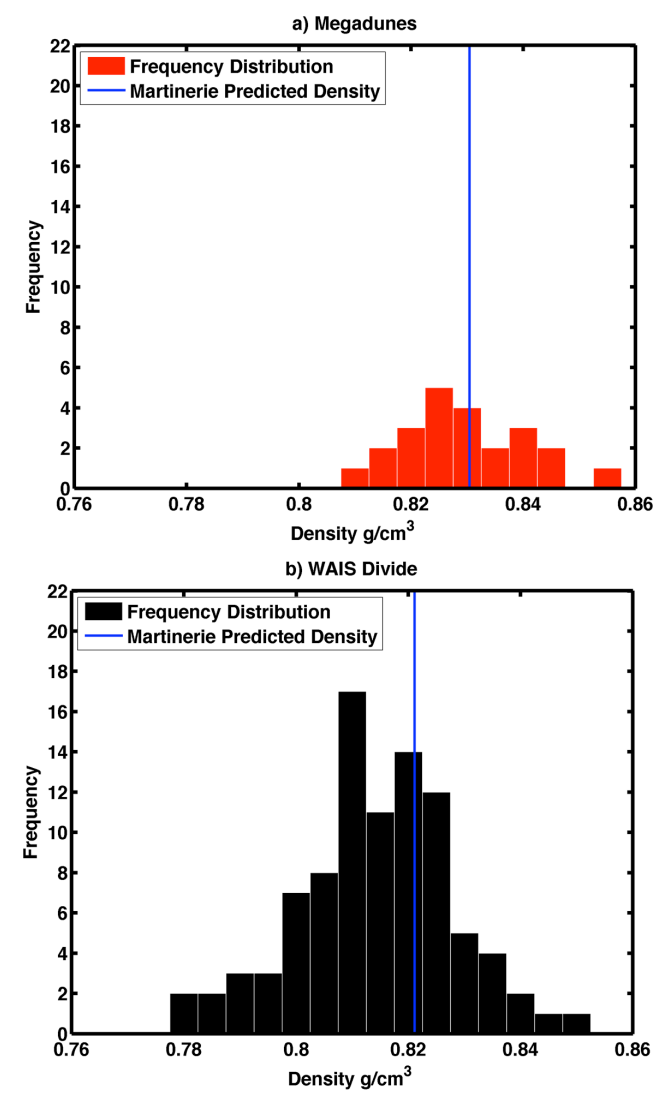

Fig. 8. Density distribution of impermeable firn samples from the LID to the end of the LIZ where all samples are impermeable at (a) Megadunes and (b) WAIS Divide.

shallower than coarser-grained layers, and a coarser-grained layer is the last permeable layer of the LIZ. Despite having a lower density and higher porosity at depth at WAIS Divide, finer-grained firn reaches pore close-off first there. Accumulation and near-surface metamorphism result in either fine-grained or coarse-grained layers and remain (independent of temperature) as identifiable features of the firn layering as they propagate down the column, leading to shallower pore close-off in fine-grain layers at WAIS Divide. In addition, the propagation of fine-grained accumulation results in shallower pore close-off at Megadunes than at other sites high on the East Antarctic plateau. In contrast, Megadunes does not exhibit a density cross-over, and initially dense fine-grained firn at surface accumulation sites on the upwind dune face remains denser than coarse-grained firn from surface hiatus sites on the leeward dune face through pore close-off (Gregory, 2013). These findings show a direct link between surface deposition microstructure and firn microstructure within the lock-in zone. It has been suggested by Hörhold et al. (2012) that impurity content is the controlling parameter on firn densification as opposed to surface microstructural characteristics. We suggest that the impurity content of the firn is simply a co-located aspect of the firn 

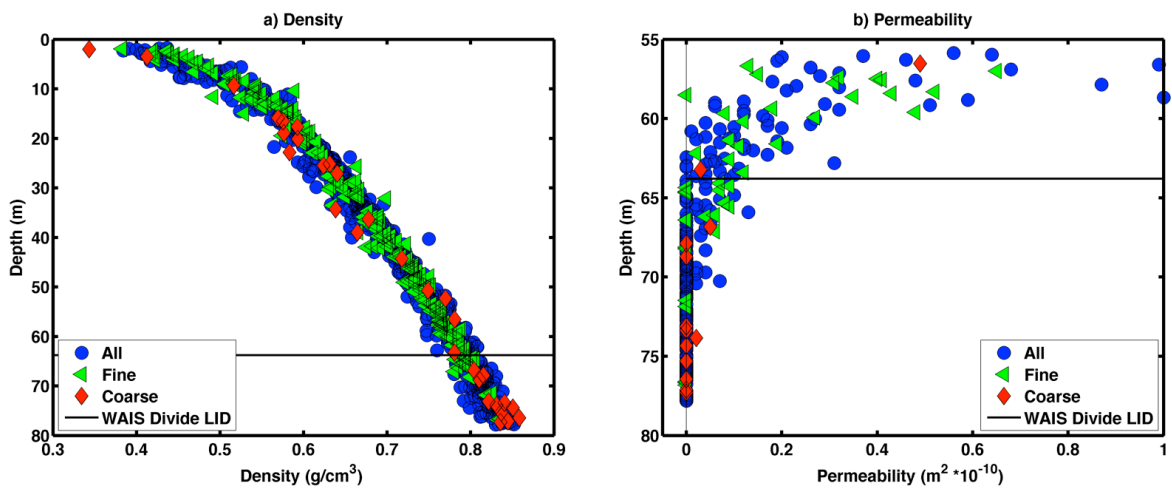

Fig. 9. (a) Density cross-over of fine- and coarse-gain firn at WAIS Divide and (b) deep firn permeability profile at WAIS Divide both show fine firn (green triangles), coarse firn (red diamonds), and intermediate firn (blue circles).

due to the depositional event, and that the impurities are not the cause of the densification rate. The fine-grained, dense firn originating from a past accumulation site at Megadunes becomes the first impermeable layers initiating the start of the LIZ. The ability of fine-grained firn to become impermeable before coarse-grained firn in this study at both WAIS Divide and Megadunes as well as in previous studies (Freitag et al., 2004), regardless of whether or not it was the predominately dense layer at depth, emphasizes the importance of grain size and pore structure when predicting gas transport and pore close-off in polar firn. A recent study by Horhold et al. (2011) correlated an increase in accumulation rate to an increase in density variability in deep firn leading to longer LIZs. While we agree that density variability due to layering does indeed increase for high-accumulation sites, the density cross-over seen in most polar firn sites leads to an inverse relationship of density and microstructure in deep firn where fine-grained layers are less dense than coarse-grained layers. Because they are both based on the layering and are originally due to the nature of accumulation rate when that firn was on the surface, microstructure will likely have high layer-to-layer variability in places where layering also makes the density variable. At a given site, the microstructure variability between fine-grained and coarse-grained layers, likely of the same magnitude of the density variability observed by Horhold et al. (2011), controls the thickness of the LIZ. For a given polar site, fine-grained layers will reach pore closeoff at shallower depths than coarse-grained layers at that site. To capture this behavior, firn densification models should include two pore close-off densities, one corresponding to the finest-grained layers that will predict the LID and one corresponding to the coarsest-grained layers that will predict the COD. In this way, the LID, COD, and LIZ thickness estimates can be improved, based on the accumulation rate of a site and the resulting microstructure variability. The very distinct layering contrast between the relic surface accumulation and hiatus zones at Megadunes provide a stark indicator of the importance of accumulation rate on the microstructure- dominated lock-in and close-off depths. While Megadunes is unique due to the presence of buried antidunes, very low accumulation will exhibit less microstructure variability in deep firn in conjunction with less density variability observed by Horhold et al. (2011) for low-accumulation sites. High-accumulation sites should, on the other hand, exhibit a higher degree of microstructure variability resulting in a greater depth difference between fine-grain close-off (LID) and coarse-grain close-off (COD). Quantifying the magnitude of microstructure variability within the lock-in zone for a large number of polar sites would be a first step in developing a firn densification model that incorporates two pore close-off depths, one for the finest-grain layers of a site and one for the coarsest-grain layers of a site. A relationship could be developed between the magnitude of grain size variability, lock-in zone length, accumulation rate, and temperature at a given polar site. We will pursue these ideas in future work.

For a physical description of why fine-grain firn reaches pore close-off first, we hypothesize that the grain size of the ice and neck size of the pore structure in firn leads to a threshold in open porosity corresponding to pore closeoff in a single layer of firn. Freitag et al. (2004) found that coarse-grained layers densify at a quicker rate than finegrained layers but that the pore size of both layers decreased at the same rate. Our findings show that whichever layer has smaller pores at the surface (the fine-grained layer) will close off first. Rick and Albert (2004) and Courville et al. (2007) both found that buried layers retain evidence of their character when they were in the near-surface firn in proportion to the amount of time that crystals remain in the near surface due to the local accumulation rate. The larger grains at Megadunes and subsequent larger pore necks enable the firn at Megadunes to reach a higher density and lower open porosity of $\sim 8 \%$, beneath which the open pore space is quickly dissected into many smaller closed pores. Due to the unique depositional process at Megadunes and the presence of hiatus sites the $\sim 8 \%$ bound on open porosity is likely 

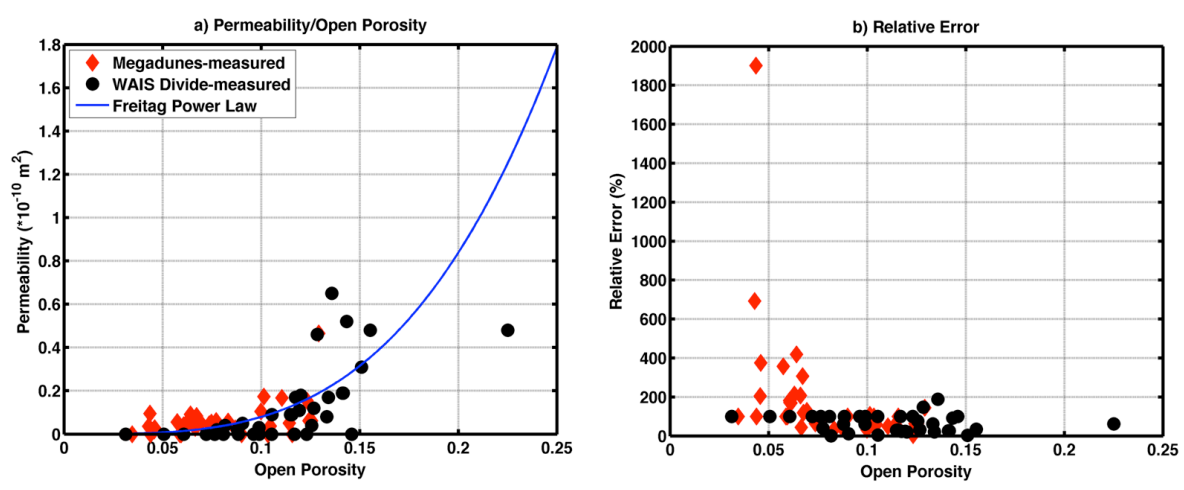

Fig. 10. (a) Measured and predicted (blue line; Freitag et al., 2002) permeability values and (b) relative error for Megadunes (red diamonds) and WAIS Divide (black circles).

lower than a more typical low-accumulation site. At WAIS Divide, the open porosity threshold occurs higher at $\sim 11 \%$ open porosity, due to the smaller ice grains and smaller necks in the pore structure. For a given accumulation rate, fine-grained firn will have the highest open porosity at pore close-off, coarse-grained firn layers will have the lowest open porosity at pore close-off and intermediate grain size layers should have open porosity thresholds for close-off in between the two extremes. Expanding this relationship across many accumulation rates, high-accumulation rates typically lead to generally smaller grains and should have higher open porosity $(\sim>10 \%)$ and lower density at pore close-off, while very low accumulation sites with larger grains should have lower open porosity $(\sim<10 \%)$ and higher density at pore closeoff. The exact physics controlling the sudden pore dissection seen at the open porosity thresholds we observed will be explored further in future studies.

\subsection{Application to firn air models}

Increasing the understanding of the impact of microstructure on gas diffusivity in deep firn through the LIZ should decrease the necessity for inverse modeling based on presentday firn air measurements within firn gas transport models. Initial gas diffusivity profiles within polar firn are typically modeled off the Schwander et al. (1988) parameterization of firn tortuosity as a function of porosity, despite recognition by Fabre et al. (2000) that tortuosity profiles are site dependent. An attempt to model permeability and diffusivity on the millimeter-to-centimeter scale as a function of open porosity was done by Freitag et al. (2002) on 3-D reconstructed firn cubes. The permeability constant $\mathrm{k}$ was fitted to open porosity following the power law commonly used in porous media with exponents experimentally determined:

$k=10^{-7.7} n_{\mathrm{op}}^{3.4}$,

where $n_{\mathrm{op}}$ is the open porosity of the sample (Freitag et al., 2002). The power law fit allowed the firn to be permeable below 0.12 open porosity, the threshold for permeable firn in previous studies done by Fabre et al. (2000) and Schwander et al. (1988). Adolph and Albert (2013) show that the Freitag et al. (2002) relationship is site-specific.

Plotting permeability data for Megadunes and WAIS Divide in Fig. 10 shows high scatter around the power law fit from measured permeability for both sites, though the general curve of the power law can be seen. The power law function fails most at low open porosity values $(5-10 \%)$ at Megadunes, where the firn is 200-1900\% more permeable than predicted with the power law function. At low open porosities, the Megadunes firn microstructure lends itself to large pores with low complexity resulting in more permeable firn than the Freitag et al. (2002) model could predict. Comparison of the Megadunes data with the Freitag et al. (2002) Greenland study shows that the relationships developed for Greenland do not apply to the Megadunes site in East Antarctica. Pore structure, which is dependent on grain size and accumulation rate, influences gas transport in the diffusive column and also controls pore close-off. The low-accumulation rate, large grain size, and larger less tortuous pore structure at Megadunes enables the firn to be much more permeable than predicted by Freitag et al. (2002). As WAIS Divide has a local climate very similar to Greenland, the error between modeled and measured permeability is not as large. Our results show that at both WAIS Divide and Megadunes, firn layers at a given open porosity display a range of permeabilities due to the open pore structure and its dependence on grain size variability. This span in permeability values at a constant open porosity would likely be seen in other polar firn profiles as well.

In deep firn it has been shown that diffusivity and permeability are linearly related (Adolph and Albert, 2013), and thus the connection between permeability and grain size/pore structure can be extrapolated to diffusivity. Firn air models that use density profiles derived from firn densification models to determine the open porosity which is then used to calculate the effective diffusivity profile of a specific gas (Buizert et al., 2012b) will fall short of capturing the true 
nature of gas transport in deep firn. A given open porosity at a high-accumulation site will lead to lower observed gas diffusivity than the diffusivity observed at a low-accumulation site. The microstructure must be accounted for to improve physics-based models of diffusivity in polar firn. The dependence of microstructure on post-depositional effects of accumulation rate and near-surface residence time observed by Albert et al. (2004), Rick and Albert (2004), Courville et al. (2007), and Fujita et al. (2009), along with an increase in gas transport due to an increase in grain size shown in this study, will in the future be used to create site-specific effective gas diffusivity profiles. A gas diffusivity profile derived from local climate parameters, specifically accumulation rate, which captures gas transport dependence on pore structure, could provide constraints for forward firn air modeling. If the physics of forward firn air modeling can be accurately captured through climate parameters, it should reduce the need for inverse modeling and enhance the ability of forward modeling to describe past firn columns where inverse modeling is not plausible.

\section{Conclusions}

Microstructure, specifically open pore structure, and not density, is the main parameter controlling the permeability and gas transport in polar firn. Pore structure is the direct result of microstructure resulting from the initial depositional processes and post-depositional metamorphism controlled by accumulation rate when the firn was near the surface of the ice sheet. Pore close-off will occur when the pore structure restricts air movement, causing the firn layer to become impermeable independent of the density of the layer. At typical firn sites, of both high and low accumulation, where a density inversion of the firn column exists, the finer, less dense firn layers will reach pore close-off shallower than coarsegrained, denser layers below the density inversion. Therefore, the shallowest fine-grained layers to close at a polar site with a density cross-over will contain more air than the coarse-grain layers, which close off deeper and at higher densities. At unique sites such as Megadunes, where no inversion is seen, pore close-off will occur shallower in the denser, finer-grained firn layers, causing the first layers to close and contain less air than the less dense, coarser-grained layers that reach pore close-off deeper in the firn column. Therefore, an important aspect for determining which firn layers, coarse grain or fine grain, have the higher air content is the presence or absence of a density inversion. Because both the density variability and the microstructure variability are features of the firn layering, microstructure will have high variability at sites where high density variability also exists. Thus the microstructure has high variability in the deep firn of high-accumulation sites and low variability in deep firn of low-accumulation sites where megadune features are absent.
In consideration of pore close-off, a threshold is seen in open porosity below which pore segregation increases dramatically and permeability reduces to zero. The exact threshold varies as a result of accumulation rate impacts on near-surface grain size propagating down the firn column into deep firn. At porosities lower than the threshold ( $\geq 10 \%$ for high-accumulation sites similar to WAIS Divide, $\sim 21 \mathrm{~cm}$ weq $^{-1}$, and $\leq 10 \%$ for low-accumulation sites similar to Megadunes, $4 \mathrm{~cm}$ weq $\mathrm{a}^{-1}$ or less), closed porosity increases rapidly, the total number of pores increases at a greater rate, and the size of pores dramatically decreases, resulting in many small pores opposed to a few large open pores.

These results could be incorporated into next-generation firn air models. First, two pore close-off densities should be incorporated, one for the finest-grained layers at an individual site which would define the top of the LIZ (the LID), and one for coarsest-grained layers at that same site which would define the bottom of the LIZ (the COD). Parameterizing pore close-off with both grain size and density, along with the layered nature of firn in firn densification models, would improve their ability to accurately predict the LID and LIZ thickness. Future studies examining relationships between surface temperature, accumulation rate and density of both coarse-grain and fine-grain layers at the surface, and when each layer type becomes impermeable at a multitude of polar sites, are necessary to create a parameterization based on both grain size and density.

For a given density, coarse-grain firn is more permeable than fine-grain firn due to a less complex and less tortuous pore structure. Next-generation firn air models should include an effective open porosity that accounts for differences in pore structure between high- and low-accumulation-rate sites. An effective open porosity that reflects the pore structure of the site, not simply how much pore space is present, and that correctly captures permeability in deep firn may provide better modeling to contribute to improved interpretation of gas records in ice cores. An increase in the physical understanding of pore close-off in polar firn and its dependence upon local climate enables next-generation firn air modeling under conditions with no present-day analogue, thus constraining the gas age-ice age difference. In ongoing work we will examine data from sites with a variety of local climates in order to further develop the dependence of gas transport and pore close-off on pore structure, grain size, and climatic condition.

Acknowledgements. This research was funded by NSF grants ANT-0944078 and IGERT-0801490. The authors thank Jeff Severinghaus, Zoe Courville and colleagues from the WAIS Divide program for useful discussions, and we thank undergraduate students Emily Harwell, Noah Pfister, and Melina Bartels for assistance with the cold room measurements.

Edited by: M. van den Broeke 


\section{References}

Albert, M. R., Schultz, E. F., and Perron, F. E. J.: Snow and firn permeability at siple dome, Antarctica, Ann. Glaciol., 31, 353356, 2000.

Adolph, A. C. and Albert, M. R.: The physical basis for gas transport through polar firn: a case study at Summit, Greenland, The Cryosphere Discuss., 7, 2455-2487, doi:10.5194/tcd7-2455-2013, 2013.

Albert, M. R., Shuman, C., Courville, Z., Bauer, R., Fahnestock, M., and Scambos,T.: Extreme firn metamorphism: Impact of decades of vapor transport on near-surface firn at a low-accumulation glazed site on the East Antarctic Plateau, Ann. Glaciol., 39, 7378, 2004.

Banta, J., McConnell, J., Frey, M., Bales, R., and Taylor, K.: Spatial and temporal variability in snow accumulation at the West Antarctic Ice Sheet Divide over recent centuries, J. Geophys. Res., 113, D23102, doi:10.1029/2008JD010235, 2008.

Battle, M. O., Severinghaus, J. P., Sofen, E. D., Plotkin, D., Orsi, A. J., Aydin, M., Montzka, S. A., Sowers, T., and Tans, P. P.: Controls on the movement and composition of firn air at the West Antarctic Ice Sheet Divide, Atmos. Chem. Phys., 11, 1100711021, doi:10.5194/acp-11-11007-2011, 2011.

Breton, D.: Photonic non-destructive measurement methods for investigating the evolution of polar firn and ice, $\mathrm{PhD}$ Thesis, University of Maine, 2011.

Brook, E. J.: Leads and lags at the end of the last Ice Age, Science, 339, 1042-1043, 2013.

Buizert, C., Martinerie, P., Petrenko, V. V., Severinghaus, J. P., Trudinger, C. M., Witrant, E., Rosen, J. L., Orsi, A. J., Rubino, M., Etheridge, D. M., Steele, L. P., Hogan, C., Laube, J. C., Sturges, W. T., Levchenko, V. A., Smith, A. M., Levin, I., Conway, T. J., Dlugokencky, E. J., Lang, P. M., Kawamura, K., Jenk, T. M., White, J. W. C., Sowers, T., Schwander, J., and Blunier, T.: Gas transport in firn: multiple-tracer characterisation and model intercomparison for NEEM, Northern Greenland, Atmos. Chem. Phys., 12, 4259-4277, doi:10.5194/acp-12-4259-2012, 2012a.

Buizert, C., Martinerie, P., Petrenko, V. V., Severinghaus, J. P., Trudinger, C. M., Witrant, E., Rosen, J. L., Orsi, A. J., Rubino, M., Etheridge, D. M., Steele, L. P., Hogan, C., Laube, J. C., Sturges, W. T., Levchenko, V. A., Smith, A. M., Levin, I., Conway, T. J., Dlugokencky, E. J., Lang, P. M., Kawamura, K., Jenk, T. M., White, J. W. C., Sowers, T., Schwander, J., and Blunier, T.: Gas transport in firn: multiple-tracer characterisation and model intercomparison for NEEM, Northern Greenland, Atmos. Chem. Phys., 12, 4259-4277, doi:10.5194/acp-12-4259-2012, 2012 b.

Clark, I. D., Henderson, L., Chappellaz, J., Fisher, D., Koerner, R., Worthy, D. E. J., Kotzer, T., Norman, A.-L., and Barnola, J.-M.: $\mathrm{CO}_{2}$ isotopes as tracers of firn air diffusion and age in an arctic ice cap with summer melting, devon island, canada, J. Geophys. Res., 112, D01301, doi:10.1029/2006JD007471, 2007.

Coleou, C., Lesaffre, B., Brzoska, J. B., Ludwig, W., and Boller, E.: Three-dimensional snow images by X-ray microtomography, Ann. Glaciol., 32, 75-81, 2001.

Courville, Z. R., Albert, M. R., Fahnestock, M. A., Cathles IV, L. M., and Shuman, C. A.: Impacts of an accumulation hiatus on the physical properties of firn at a low-accumulation polar site, J. Geophys. Res., 112, F02030, doi:10.1029/2005JF000429, 2007.
Courville, Z., Hörhold, M., Hopkins, M., and Albert, M.: Latticeboltzmann modeling of the air permeability of polar firn, J. Geophys. Res., 115, F04032, doi:10.1029/2009JF001549, 2010.

Entig, I. G.: Statistics of firn closure: a simulation study, J. Glaciol., 39, 133-142, 1993.

Etheridge, D. M., Steele, L. P., Langenfelds, R. L., Francey, R. J., Barnola, J. M., and Morgan, V. I.: Natural and anthropogenic changes in atmospheric co2 over the last 1000 years from air in antarctic ice and firn, J. Geophys. Res., 101, 4115-4128, 1996.

Fabre, A., Barnola, J. M., Arnaud, L., and Chappellaz, J.: Determination of gas diffusivity in polar firn: Comparison between experimental measurements and inverse modeling, Geophys. Res. Lett., 27, 557-560, 2000.

Freitag, J.: The layering of polar firn and its linkage to air trapping, Workshop on the mircostructure and properties of firn, 10 1 March 2008, Dartmouth College, Hanover, USA, 2008.

Freitag, J., Dorbrindt, U., and Kipfstuhl, J.: A new method for predicting transport properties of polar firn with respect to gases on the pore-space scale, Ann. Glaciol., 35, 538-544, doi:10.3189/172756402781816582, 2002.

Freitag, J., Wilhelms, F., and Kipfstuhl, S.: Microstructuredependent densification of polar firn derived from X-ray microtomography, J. Glaciol., 50, 243-250, 2004.

Fujita, S., Okuyama, J., Hori, A., and Hondoh, T.: Metamorphism of stratified firn at dome fuji, antarctica: A mechanism for local insolation modulation of gas transport conditions during bubble close off, J. Geophys. Res., 114, F03023, doi:10.1029/2008JF001143, 2009.

Gregory, S. A.: The impact of microstructure and physical properties on pore close-off at WAIS Divide and Megadunes, MS thesis, Dartmouth College, USA, 2013.

Goujon, C., Barnola, J. M., and Ritz, C.: Modeling the densification of polar firn including heat diffusion: Application to closeoff characteristics and gas isotopic fractionation for Antarctica and Greenland sites, J. Geophys. Res.-Atmos, 108, 4792, doi:10.1029/2002JD003319, 2003.

Hildebrand, T. and Rüegsegger, P.: Quantification of bone microarchitecture with the structure model index, Comput. Meth. Biomech. Biomed. Eng., 1, 15-23, 1997.

Hörhold, M. W., Kipfstuhl, S., Wilhelms, F., Freitag, J., and Frenzel, A.: The densification of layered polar firn, J. Geophys. Res. Earth Surf., 116, F01001, doi:10.1029/2009JF001630, 2011.

Hörhold, M. W., Laepple, T., Freitag, J., Bigler, M., Fischer, H., and Kipfstuhl, S.: On the impact of impurities on the densification of polar firn, Earth Planet Sc. Lett., 325-326, 93-99, 2012.

Kawamura, K., Severinghaus, J. P., Ishidoya, S., Sugawara, S., Hashida, G., Motoyama, H., Fujii, Y., Aoki, S., and Nakazawa, T.: Convective mixing of air in firn at four polar sites, Earth Planet Sc. Lett., 244, 672-682, 2006.

Landais, A., Barnola, J. M., Kawamura, K., Caillon, N., Delmotte, M., Van Ommen, T., Dreyfus, G., Jouzel, J., Masson-Delmotte, V., Minster, B., Freitag, J., Leuenberger, M., Schwander, J., Huber, C., Etheridge, D., and Morgan, V.: Firn-air delta n-15 in modern polar sites and glacial-interglacial ice: a model-data mismatch during glacial periods in antarctica?, Quaternary Sci. Rev., 25, 49-62, 2006.

Lomonaco, R., Albert, M., and Baker, I.: Microstructural evolution of fine-grained layers through the firn column at Summit, Greenland, J. Glaciol., 57, 755-762, 2011. 
Martinerie, P., Raynaud, D., Etheridge, D. M., Barnola, J. M., and Mazaudier, D.: Physical and climatic parameters which influence the air content in polar ice, Earth Planet Sc. Lett., 112, 1-13, 1992.

Rick, U. and Albert, M. R.: Firn microstructure impacts on air permeability, ERDC-CRREL Tech. Rep. TR-96, 79 pp., Cold Reg. Res. and Eng. Lab., Hanover, NH, 2004.

Rommelaere, V., Arnaud, L., and Barnola, J. M.: Reconstructing recent atmospheric trace gas concentrations from polar firn and bubbly ice data by inverse methods, J. Geophys. Res.-Atmos., 102, 30069-30083, 1997.

Schneebeli, M. and Sokratov, S. A.: Tomography of temperature gradient metamorphism of snow and associated changes in heat conductivity, Hydrol. Process., 18, 3655-3665, 2004.

Schwander, J. and Stauffer, B.: Age difference between polar ice and the air trapped in its bubbles, Nature, 311, 45-47, 1984.

Schwander, J., Stauffer, B., and Sigg, A.: Air mixing in firn and the age of the air at pore close-off, Ann. Glaciol., 10, 141-145, 1988.

Schwander, J., Barnola, J. M., Andrie, C., Leuenberger, M., Ludin, A., Raynaud, D., and Stauffer, B.: The age of the air in the firn and the ice at summit, greenland, J. Geophys. Res.-Atmos., 98, 2831-2838, 1993.

Severinghaus, J. P., Grachev, A., and Battle, M.: Thermal fractionation of air in polar firn by seasonal temperature gradients, Geochem. Geophy. Geosy., 2, 1048, doi:10.1029/2000GC000146, 2001.

Severinghaus, J. P., Albert, M. R., Courville, Z. R., Fahnestock, M. A., Kawamura, K., Montzka, S. A., Muhle, J., Scambos, T. A., Shields, E., Shuman, C. A., Suwa, M., Tans, P., and Weiss, R. F.: Deep air convection in the firn at a zero-accumulation site, central antarctica, Earth Planet Sc. Lett., 293, 359-367, 2010.
Sowers, T., Bender, M., Raynaud, D., and Korotkevich, Y. S.: Delta$\mathrm{n}-15$ of $\mathrm{n} 2$ in air trapped in polar ice - a tracer of gas-transport in the firn and a possible constraint on ice age-gas age-differences, J. Geophys. Res.-Atmos., 97, 15683-15697, 1992.

Spaulding, N. E., Meese, D. A., and Baker, I.: Advanced microstructural characterization of four East Antarctic firn/ice cores, J. Glaciol., 57, 796-810, 2011.

Taina, I. A., Heck, R. J., and Elliot, T. R.: Application of X-ray computed tomography to soil science: a literature review, Can. J. Soil Sci., 88, 1-20, 2008.

Trudinger, C. M.: The carbon cycle over the last 1000 years inferred from inversion of ice core data, $\mathrm{PhD}$ thesis, Monash University, Australia, 2001.

Trudinger, C. M., Enting, I. G., Etheridge, D. M., Francey, R. J., Levchenko, V. A., Steele, L. P., Raynaud, D., and Arnaud, L.: Modeling air movement and bubble trapping in firn, J. Geophys. Res.-Atmos., 102, 6747-6763, 1997.

Trudinger, C. M., Etheridge, D. M., Rayner, P. J., Enting, I. G., Sturrock, G. A., and Langenfelds, R. L.: Reconstructing atmospheric histories from measurements of air composition in firn. J. Geophys. Res.-Atmos., 107, 4780, doi:10.1029/2002JD002545, 2002.

Witrant, E., Martinerie, P., Hogan, C., Laube, J. C., Kawamura, K., Capron, E., Montzka, S. A., Dlugokencky, E. J., Etheridge, D., Blunier, T., and Sturges, W. T.: A new multi-gas constrained model of trace gas non-homogeneous transport in firn: evaluation and behaviour at eleven polar sites, Atmos. Chem. Phys., 12, 11465-11483, doi:10.5194/acp-12-11465-2012, 2012. 